\title{
Astrocytes amplify neuronal dendritic volume transmission
}

\author{
Chun Chen ${ }^{1 \#}$, ZhiYing Jiang ${ }^{1 \#}$, Xin Fu ${ }^{1,2}$, and Jeffrey G. Tasker ${ }^{1,2^{*}}$ \\ ${ }^{1}$ Department of Cell \& Molecular Biology and ${ }^{2}$ Tulane Brain Institute, Tulane University, \\ New Orleans, LA, 70118
}

Running title: Astrocytes expand volume transmission

Abstract: 128 words; Intro: 483 words; Discussion: 1,389 words; Total: 5,014 words

*Corresponding Author: Jeff Tasker, Dept. of Cell \& Molecular Biology, Tulane University, New Orleans, LA 70118; tel: (504) 862-8726; email: tasker@ tulane.edu \# Contributed equally to this study

Current address for ZhiYing Jiang: University of Texas Health Science Center, 1825 Pressler St, SRB 401A, Houston, TX 77030

Acknowledgments: This work was supported by NIH R01 MH069879 and the Catherine and Hunter Pierson Chair in Neuroscience. We thank Dr. Laura Harrison for her help with the animal husbandry and molecular analyses, and Dr. Diankun Yu for his helpful discussion of the paper. We thank Prof. Maurice Manning for his donation of vasopressin receptor antagonist and Dr. Paul Sawchenko for his donation of CRF antibody.

Author Contributions: C.C. and Z.J. contributed equally to the experiments, data analysis, and to writing the manuscript; X.F. contributed to the experiments and edition of the manuscript; J.G.T. contributed to the design and interpretation of experiments and to writing the manuscript. 


\begin{abstract}
In addition to their support role in neurotransmitter and ion buffering, astrocytes directly regulate neurotransmission at synapses via local bidirectional signaling with neurons. Here, we reveal a new form of neuronal-astrocytic signaling that transmits retrograde dendritic signals to upstream neurons to activate recurrent synaptic circuits. Norepinephrine activates $\alpha_{1}$-adrenoreceptors in hypothalamic corticotropin releasing factor $(\mathrm{CRF})$ neurons to stimulate dendritic release, which triggers an astrocytic calcium response and release of ATP; ATP stimulates action potentials in upstream glutamate and GABA neurons to activate recurrent excitatory and inhibitory synaptic circuits to the CRF neurons. Thus, norepinephrine activates a novel retrograde signaling mechanism in CRF neurons that engages astrocytes in order to extend dendritic volume transmission to reach distal presynaptic glutamate and GABA neurons, thereby amplifying volume transmission mediated by dendritic release.
\end{abstract}

Key words: norepinephrine, noradrenaline, CRF, CRH, hypothalamus, paraventricular nucleus, astrocyte, glia, vasopressin, stress 


\section{Introduction}

The functional role of astrocytes is not limited to buffering extracellular ions and neurotransmitters, but also includes an active involvement in neurotransmission. Astrocytes interact with neurons by responding to neurotransmitters and by releasing gliotransmitters ${ }^{1}$. However, the neuron-astrocyte interaction has been largely limited to the tripartite synapse, or neuronal pre- and postsynaptic elements and surrounding astrocyte (Araque et al., 1999; Halassa et al., 2007). Astrocytic calcium signals can be transmitted through branched astrocyte arbors (Cornell-Bell et al., 1990; Charles et al., 1991; Porter and McCarthy, 1996) or can be localized to subdomains within branches (Haustein et al., 2014; Shigetomi et al., 2013), giving astrocytes the potential to signal remotely from the response generation site, and electrical coupling via gap junctions extends this capacity beyond the limits of the astrocytic arbor ${ }^{9}$. Whether astrocytes transmit neuron-derived signals distally is currently not known.

Volume neurotransmission is mediated by diffusion of neurotransmitter away from its release site, and can be orthograde, between the presynaptic terminal and postsynaptic soma/dendrite, or retrograde, from the postsynaptic dendrite to the presynaptic neuron. It is spatially constrained by astrocytic buffering and enzymatic degradation (Di et al., 2013; Wu and Tasker, 2017; Son et al., 2013). Pioneering research on hypothalamic neuroendocrine cells demonstrated retrograde volume transmission of the neuropeptides oxytocin and vasopressin, which exerts localized paracrine actions on presynaptic neurotransmitter release (Ludwig et al., 2002; Kombian et al., 1997; Oliet et al., 2007; de Kock et al., 2003). We reported that vasopressin released from vasopressin neuron dendrites activates a calcium signal in astrocytes that leads to stimulation of 
presynaptic GABA neurons (Haam et al., 2014).

The hypothalamic-pituitary-adrenal (HPA) axis comprises the neuroendocrine stress response, producing systemic glucocorticoid secretion from the adrenals following corticotropin-releasing factor $(\mathrm{CRF})$ secretion from the hypothalamic paraventricular nucleus (PVN) and adrenocorticotrophic hormone secretion from the pituitary. Brainstem noradrenergic systems provide a major excitatory drive to the HPA axis. Anatomical and physiological studies indicate that $\mathrm{CRF}$ neurons receive direct noradrenergic innervation (Itoi et al., 1994; Plotsky, 1987; Cole and Sawchenko, 2002; Itoi et al., 1999; Helmreich et al., 2001; Sawchenko and Swanson, 1982; Cunningham and Sawchenko, 1988; Flak et al., 2014; Woulfe et al., 1990; Flak et al., 2009; Herman et al., 2004; Ziegler et al., 2012), and medial parvocellular neurons express $\alpha_{1}$-adrenoreceptors (Cummings and Seybold, 1988; Day et al., 1997). In contrast, electrophysiological studies indicate that norepinephrine excites parvocellular neurons indirectly via activation of local synaptic circuits (Daftary et al., 2000; Han et al., 2002). Thus, despite multiple efforts, the mechanism of the noradrenergic activation of the HPA axis remains elusive.

Here, we investigated the cellular mechanisms of the norepinephrine excitation of CRF neurons using whole-cell recordings in brain slices. We found that norepinephrine elicits the dendritic release of vasopressin from the CRF neurons to activate an astrocytic relay to presynaptic glutamate and GABA neurons, revealing a previously unidentified astrocytic amplification of retrograde volume transmission. 


\section{Results}

\section{NE activation of CRF neurons}

Extracellular loose-seal, cell-attached patch clamp recordings were performed in CRF neurons to record the spontaneous spiking activity. Bath application of norepinephrine (NE, $100 \mu \mathrm{M}, 5 \mathrm{~min}$ ) significantly increased the firing frequency of CRFeGFP neurons $(\mathrm{p}<0.01)$, which was suppressed in the glutamate receptor antagonists DNQX $(15 \mu \mathrm{M})$ and AP5 $(50 \mu \mathrm{M})(\mathrm{p}=0.37)$ and enhanced in picrotoxin $(50 \mathrm{mM})$, though this did not reach significance (Two-way ANOVA, F $(2,33)=3.522, \mathrm{p}=0.04$, followed by Bonferroni's multiple comparisons) (Fig. 1A-C). To test whether the excitation of CRF neurons is mediated by NE modulation of synaptic inputs, we recorded spontaneous EPSCs (sEPSCs) and IPSCs (sIPSCs) in CRF neurons. sEPSCs had a basal mean frequency of $1.56 \pm 0.10 \mathrm{~Hz}$, amplitude of $19.13 \pm 0.50 \mathrm{pA}$, and decay time of 2.18 $\pm 0.06 \mathrm{~ms}(\mathrm{n}=47)$; bath application of $\mathrm{NE}(100 \mu \mathrm{M}, 5 \mathrm{~min})$ evoked a robust increase in the frequency of $\operatorname{sEPSCs}(335.2 \pm 61.5 \%$ of baseline at $100 \mu \mathrm{M}, \mathrm{n}=17, \mathrm{p}<0.01)$, without causing a change in sEPSC amplitude $(\mathrm{p}=0.14)$ or decay time $(\mathrm{p}=0.58)$ (Fig. 1D, E; Supplemental Fig. 2A), which suggested a possible presynaptic site of action. The NE stimulation of excitatory synaptic inputs to CRF neurons was concentrationdependent, with a threshold concentration of $\sim 100 \mathrm{nM}(118.7 \pm 7.99 \%$ of baseline, $\mathrm{n}=9$, $\mathrm{p}=0.047)($ Fig. 1F). It was also action potential-dependent, since blockade of voltagegated $\mathrm{Na}^{+}$channels with tetrodotoxin (TTX, $1 \mu \mathrm{M}$ ) abolished the NE-induced increase in sEPSC frequency $(92.4 \pm 9.0 \%$ of baseline, $n=9, p=0.42)$ (Fig. 1G).

The sIPSCs in CRF-eGFP neurons had a basal mean frequency of $0.86 \pm 0.10 \mathrm{~Hz}$, 
amplitude of $51.23 \pm 3.82 \mathrm{pA}$, and decay time of $12.72 \pm 0.54 \mathrm{~ms}(\mathrm{n}=20)$. Norepinephrine (100 $\mu \mathrm{M}, 5 \mathrm{~min})$ induced two distinct effects on sIPSCs in separate cohorts of CRF neurons: $55 \%$ of CRF neurons (11/20) showed a $\sim 75 \%$ increase in sIPSC frequency $(\mathrm{p}<$ $0.01)$ and $45 \%(9 / 20)$ showed a $\sim 50 \%$ decrease in sIPSC frequency $(\mathrm{p}<0.01)($ Fig. $1 \mathrm{H}, \mathrm{I})$, with no effect on sIPSC amplitude $(\mathrm{p}=0.53)$ or decay time $(\mathrm{p}=0.12)$ (Supplementary Fig. 2B). The NE-induced increase in sIPSC frequency was not seen in any CRF neurons recorded in the presence of TTX, and all of the cells showed a decrease in the sIPSC frequency $(65.14 \% \pm 2.78 \%, \mathrm{n}=8, \mathrm{p}<0.01)$ (Fig. 1J). Thus, the NE facilitation of inhibitory synaptic inputs to CRF neurons is action potential-dependent, while the NEinduced suppression of inhibitory synaptic inputs is action potential-independent. The facilitatory effect of $100-\mu \mathrm{M}$ NE on GABA release in some cells, therefore, masked the NE-induced suppression of GABA release, which occurred in all CRF neurons tested. The absence of the spike-dependent facilitatory response in some CRF neurons suggested that the axons of the NE-sensitive presynaptic neurons were cut in those slices.

The two effects of NE on synaptic inhibition had different concentration sensitivities. Nearly all the CRF neurons (14/16 cells) responded to NE with either no response or a suppression of sIPSCs at the lowest concentrations tested (100 nM and 1 $\mu \mathrm{M})$, and the proportion of cells that responded with a facilitation of sIPSCs increased at higher NE concentrations $(2 / 9$ cells $(22 \%)$ at $10 \mu \mathrm{M}$ and $11 / 20$ cells $(55 \%)$ at $100 \mu \mathrm{M})$ (Fig. 1K). Thus, the spike-dependent NE facilitation of GABA release had a higher threshold $(\sim 10 \mu \mathrm{M})$ than the spike-independent NE suppression of GABA release $(<100$ $\mathrm{nM})$. Note that the threshold for facilitation of excitatory synaptic inputs $(\sim 100 \mathrm{nM})$ was over an order of magnitude lower than the threshold for NE facilitation of inhibitory 
synaptic inputs to the CRF neurons. Additionally, the NE activation of inhibitory synaptic inputs was less robust than the activation of excitatory synaptic inputs, which accounts for the net excitatory effect of NE on the CRF neuron spiking.

\section{$\alpha_{1}$-adrenoreceptor dependence of the norepinephrine facilitation of excitatory} synaptic inputs to CRF neurons

We next investigated the adrenoreceptor dependence of the NE facilitation of excitatory synaptic inputs to CRF neurons. Bath application of the $\alpha_{1}$-adrenoreceptor antagonist prazosin $(10 \mu \mathrm{M})$ alone caused a small decrease in sEPSC frequency $(85.2 \pm$ $5.5 \%$ of baseline, $\mathrm{n}=9, \mathrm{p}=0.027$ ), suggesting a tonic activation of $\alpha_{1}$ adrenoreceptors by ambient endogenous NE (or epinephrine). Prazosin abolished the NE-induced increase in sEPSC frequency $(\mathrm{p}=0.35, \mathrm{n}=9)$ (Fig. 2A, C). Bath application of the $\alpha_{1}$ adrenoreceptor agonist phenylephrine $(100 \mu \mathrm{M})$ for 5 min caused an increase in sEPSC frequency $(424.2 \pm 106.2 \%$ of baseline, $n=8, p=0.019)$ similar to that induced by NE (NE vs. PE, $\mathrm{p}=0.45$ ), although it did not reverse with a 20-min washout (Fig. 2B, C). Taken together, these results indicate that the NE-induced facilitation of sEPSCs in CRF neurons is mediated by $\alpha_{1}$-adrenoreceptor activation.

$\alpha_{1-}$ and $\alpha_{2}$-adrenoreceptor dependence of the norepinephrine modulation of inhibitory synaptic inputs to CRF neurons

In recordings of sIPSCs in the presence of DNQX and AP5, bath application of the $\alpha_{1}$ adrenoreceptor antagonist prazosin $(10 \mu \mathrm{M})$ alone caused a significant decrease in the sIPSC frequency compared to baseline $(81.82 \% \pm 6.33 \%$ of baseline, $n=8, p=0.02)$, 
again suggesting a tonic activation of $\alpha_{1}$-adrenoceptors and modulation of GABA release by endogenous NE. Norepinephrine $(100 \mu \mathrm{M})$ failed to elicit an increase in sIPSC frequency following preapplication of prazosin, but all $8 \mathrm{CRF}$ neurons recorded in prazosin responded with a significant decrease in sIPSC frequency $(36.31 \% \pm 5.01 \%$ of baseline, $\mathrm{n}=8, \mathrm{p}<0.01$ ) (Fig. 2D, E). This indicated that the NE facilitation of IPSCs, like the facilitation of EPSCs, is mediated by $\alpha_{1}$-adrenoreceptor activation, whereas the NE-induced suppression of IPSCs is $\alpha 1$-receptor independent. The NE-induced suppression of sIPSCs was greater in the presence of prazosin $(51 \%$ of baseline without prazosin vs. $36 \%$ of baseline with prazosin) and this difference showed a strong trend towards significance $(\mathrm{p}=0.050)$ (Fig. 2E), which supports a model of opposing NE regulation of GABA release onto CRF neurons.

Because the NE facilitation, but not suppression, of GABA release was spikedependent, we blocked the facilitatory response with TTX $(1 \mu \mathrm{M})$ to isolate the NEinduced suppression of GABA release. In the presence of TTX, preapplication of the $\alpha_{2}$ adrenoreceptor antagonist yohimbine $(20 \mu \mathrm{M})$ alone had no effect on sIPSC frequency, but completely blocked the NE-induced decrease in SIPSC frequency $(103.8 \% \pm 10.57 \%$, $\mathrm{n}=8, \mathrm{p}=0.86)($ Fig. $2 \mathrm{~F}, \mathrm{G})$. Thus, at lower concentrations, NE activates presynaptic $\alpha_{2}$ adrenoreceptors to suppress GABA release and, at higher concentrations, it also activates $\alpha_{1}$ adrenoreceptors to stimulate spiking in presynaptic GABA neurons and an increase in GABA release onto PVN CRF neurons.

\section{Localization of adrenoreceptors to pre- and postsynaptic loci}

Our data suggest that NE causes a spike-dependent increase in excitatory and 
inhibitory synaptic inputs to PVN CRF neurons by acting at $\alpha 1$ adrenoreceptors on local presynaptic glutamate and GABA neurons, respectively. However, considerable immunohistochemical evidence exists for noradrenergic synapses directly on CRF neurons (Flak et al., 2009; Liposits et al., 1986) and for $\alpha_{1}$-adrenoceptor expression by CRF neurons ${ }^{34}$. Here, we tested for the dependence of the NE effect on the activation of postsynaptic receptors by including a broad-spectrum G-protein inhibitor, GDP- $\beta$-S (1 $\mathrm{mM}$ ), in the patch electrode. The NE-induced increase in sEPSC frequency was blocked in 7 of $10 \mathrm{CRF}$ neurons (70\%) recorded with GDP- $\beta$-S-containing electrodes $(123.4 \pm$ $36.6 \%$ of baseline, $\mathrm{n}=10, \mathrm{p}=0.54$ ) (Fig. 3A, B), which suggested that the $\alpha_{1}$ adrenoceptor-induced facilitation of excitatory synaptic inputs to the CRF neurons has a postsynaptic locus. With GDP- $\beta-S$ in the patch solution and glutamate receptors blocked, only $15 \%$ of CRF neurons $(2 / 13)$ responded to NE $(100 \mu \mathrm{M})$ with an increase in sIPSC frequency, while $85 \%$ of $\mathrm{CRF}$ neurons (11/13) responded with a decrease in sIPSC frequency $(71.53 \% \pm 10.92 \%$ of baseline, $n=13, p=0.023)$ (Fig. 3C, D). The shift in the distribution of the two sIPSC responses caused by postsynaptic G-protein blockade (increase: $55 \%$ without GDP- $\beta$ s to $15 \%$ with GDP- $\beta$ s; decrease: $45 \%$ without GDP- $\beta$ s to $85 \%$ with GDP- $\beta$ s) was significant $(\mathrm{p}=0.023$, chi-squared). This suggested that the NEinduced facilitation of GABA release, like that of glutamate release, is dependent on postsynaptic $\mathrm{G}$ protein activation, whereas the NE-induced suppression of GABA release is not. Therefore, the NE facilitation of excitatory and inhibitory synaptic inputs to CRF neurons share a common mechanism: postsynaptic $\alpha_{1}$ receptor activation that results in spike generation in presynaptic glutamate and GABA neurons. The NE-induced suppression of inhibitory synaptic inputs to the CRF neurons, on the other hand, is 
mediated by the activation of presynaptic $\alpha_{2}$ adrenoreceptors and is spike-independent, indicating that it occurs at presynaptic GABA terminals. The reliance of the NE facilitation of glutamate and GABA inputs on a postsynaptic G protein-dependent mechanism suggests the recruitment of a retrograde signaling mechanism in this effect.

\section{The norepinephrine-induced facilitation of excitatory and inhibitory synaptic inputs to CRF neurons is mediated by dendritic vasopressin release}

The activation of presynaptic glutamate and GABA neurons by a postsynaptic $\alpha_{1}$ adrenoreceptor-dependent mechanism implicates the dendritic release of an excitatory retrograde messenger. We tested for the involvement of nitric oxide (NO) and CRF, but the NE effect was not dependent on either signal (Supplementary Fig. 3). Vasopressin is expressed in CRF neurons and released from CRF neuron axon terminals in the median eminence in response to different stressors and central $\alpha_{1}$-adrenoreceptor activation (Whitnall et al., 1993; de Goeij et al., 1991). We showed recently that vasopressin is released as a retrograde messenger from the dendrites of magnocellular vasopressinergic neurons in the PVN and activates a retrograde signaling mechanism that increases spikedependent GABAergic inputs to the vasopressin neurons ${ }^{37}$. Therefore, we tested for the vasopressin dependence of the NE-induced facilitation of sEPSCs. While without effect on basal sEPSCs $(\mathrm{p}=0.42)$, bath application of the vasopressin V1a receptor antagonist SR 49059 completely blocked the increase in sEPSC frequency induced by $100 \mu \mathrm{M}$ NE $(104.5 \% \pm 17.07 \%$ of baseline, $\mathrm{n}=6, \mathrm{p}=0.80)$ (Fig. 3E). We then tested for an agonistic effect of vasopressin on sEPSC frequency with pressure application of vasopressin (20 $\mu \mathrm{M})$ on the surface of the slices close to the recorded CRF neurons (8-20 psi, $30 \mathrm{~s})$. 
Vasopressin caused a robust increase in the sEPSC frequency in CRF neurons $(221.9 \% \pm$ $36.56 \%, \mathrm{n}=6, \mathrm{p}=0.021$ ) (Fig. 3E), which was not significantly different from the NEinduced increase in sEPSC frequency. These two experiments suggested that vasopressin is the messenger that is released in response to $\mathrm{NE}$ and that activates presynaptic glutamate neurons. However, the release of vasopressin from CRF neuron dendrites has not been described before and is unexpected, so we tested whether the source of vasopressin was from neighboring vasopressin neurons in the PVN. In our previous study, we found that ghrelin elicits the dendritic release of vasopressin from vasopressin neurons in the PVN, resulting in an increase in TTX-sensitive synaptic inputs to the vasopressin neurons ${ }^{37}$. Bath application of ghrelin $(100 \mathrm{nM})$ had no effect on the sEPSCs recorded in CRF neurons (frequency: $104.5 \% \pm 11.54 \%$ of baseline, $\mathrm{n}=10, \mathrm{p}=0.71$ ) (Supplementary Fig. 3B), which excluded vasopressin neurons as the source of intraPVN vasopressin and suggested that the V1a receptor-dependent NE response was mediated by vasopressin release from CRF neurons.

\section{The norepinephrine facilitation of excitatory and inhibitory inputs to CRF neurons is dependent on astrocyte activity and gliotransmission}

The spike dependence of the retrograde facilitation of excitatory and inhibitory synaptic inputs to the CRF neurons suggests that the dendritic messenger acts at a distal presynaptic somatic/dendritic locus to excite presynaptic glutamate and GABA neurons. We tested for a role of astrocytes as intermediates in the relay of the retrograde signal responsible for the NE-induced activation of presynaptic excitatory and inhibitory neurons. Fluorocitric acid (FCA) is preferentially taken up by glia and reversibly blocks 
glial metabolic function by impairing the Krebs cycle (Paulsen et al., 1987; Swanson and Graham, 1994), which inhibits glial signaling. Preincubation of slices in FCA (100 $\mu \mathrm{M})$ for 2-4 $\mathrm{h}$ prior to recordings significantly blunted the NE-induced increase in sEPSC frequency $(144.33 \% \pm 16.23 \%, \mathrm{n}=13, \mathrm{p}=0.018$ compared to baseline, $\mathrm{p}<0.01$ compared to NE effect in untreated slices) (Fig 4A, B). Preincubation of slices in FCA also blocked the NE-induced increase in sIPSC frequency, resulting in a decrease in sIPSC frequency $(74.74 \% \pm 7.78 \%$ compared to baseline, $n=10, p=0.01)($ Fig. $4 C, D)$. This suggested that the NE-induced facilitation of both excitatory and inhibitory synaptic inputs to CRF neurons is dependent on astrocyte activity.

We next tested whether the NE-induced increase in sEPSC and sIPSC frequencies is dependent on the release of the gliotransmitter ATP by blocking purinergic receptors. Bath application of PPADS $(100 \mu \mathrm{M})$, a non-selective P2 receptor antagonist, blocked the NE-induced increase in sEPSC frequency $(120.8 \pm 37.7 \%$ of baseline, $n=7, p=0.42$; NE vs. NE/PPADS: $p=0.04$ ) (Fig 4E). In recordings of sIPSCs, bath application of TNPATP $(10 \mu \mathrm{M})$, a selective $\mathrm{P}_{2} \mathrm{X}$ purinergic receptor antagonist, blocked the NE-induced increase in sIPSC frequency, sparing the NE-induced decrease in sIPSC frequency $(41.89 \%$ $\pm 3.57 \%, \mathrm{n}=6, \mathrm{p}<0.01)($ Fig. $4 \mathrm{~F})$. The $\mathrm{P}_{2} \mathrm{X}$ antagonist had no effect on the NE-induced decrease in sIPSC frequency (NE vs. TNP-ATP/NE: p = 0.12) (Fig. 4F), which was consistent with the NE-induced suppression of GABA release not being dependent on the retrograde signaling mechanism. Thus, the NE-induced facilitation of excitatory and inhibitory synaptic inputs to the CRF neurons depends on the ATP activation of $\mathrm{P}_{2} \mathrm{X}$ purinergic receptors.

To further test for the glial participation in the NE-induced facilitation of 
excitatory and inhibitory synaptic inputs, we next conducted calcium imaging experiments using the glia-specific calcium indicator Rhod-2 AM ${ }^{40}$ to examine whether NE causes a calcium response in glial cells. Slices were incubated in Rhod-2 AM (1-3 $\mu \mathrm{M})$ for 30-60 minutes to bulk load the calcium fluorophore. Norepinephrine (100 $\mu \mathrm{M}, 5$ min) induced a significant increase in the relative fluorescence intensity $(116.4 \% \pm$ $3.88 \%, \mathrm{n}=30, \mathrm{p}<0.01)$, which was blocked with a non-selective oxytocin and vasopressin receptor antagonist, Manning compound (kindly provided by Professor Maurice Manning, University of Toledo) (Fig. 4G, I). We did not use the selective V1a receptor antagonist here because it induced autofluorescence in the brain slices. We next tested whether vasopressin activates a calcium response in astrocytes. Bath application of vasopressin $(200 \mathrm{nM})$ also caused an increase in the relative fluorescence signal $(154.7 \%$ $\pm 14.38 \%, \mathrm{n}=9, \mathrm{p}<0.01)($ Fig. $4 \mathrm{H}, \mathrm{I})$. These results together suggest that NE stimulates presynaptic glutamate and GABA circuits by activating PVN astrocytes via a vasopressin V1a receptor-dependent mechanism.

The recruitment of glia into the retrograde signaling mechanism triggered by NE and the involvement of ATP as a gliotransmitter in the activation of presynaptic glutamate and GABA neurons suggested that ATP may be released from astrocytes by exocytosis. We tested this hypothesis using a transgenic mouse model (kindly provided by Dr. Phillip Haydon, Tufts University) in which exocytosis is suppressed in astrocytes by the conditional Tet-off expression of a dominant-negative synaptotagmin (dnSNARE) under the control of the glial fibrillary acidic protein promoter. The dnSNARE mice were crossed with the CRF-eGFP mice to allow us to target the CRF neurons for recording. Mice were taken off the doxycycline diet for 5 weeks to induce dnSNARE expression, 
and mice maintained on the doxycycline diet to suppress dnSNARE expression served as controls. The NE-induced increase in sEPSC frequency was maintained in CRF neurons from CRF-eGFP/dnSNARE mice kept on the doxycycline diet (on-dox/NE: $258.7 \% \pm$ $60.85 \%$ compared to baseline, $n=6, p=0.048$; on-dox/NE vs. control/NE: $p=0.50)$. In slices from CRF-eGFP/dnSNARE mice taken off the doxycycline diet, the NE-induced increase in sEPSC frequency, although still significant compared to baseline $(124.4 \% \pm$ $7.27 \%, \mathrm{n}=7, \mathrm{p}=0.015)$, was significantly suppressed compared to the NE effect in slices from mice maintained on the doxycycline diet (off-dox/NE vs. on-dox/NE: $p=$ 0.037) (Fig. 4J). This suggested that the NE-induced facilitation of glutamate release onto CRF neurons is suppressed by blocking exocytosis in astrocytes.

\section{Modulation of excitatory and inhibitory synaptic inputs to CRF neurons by endogenous norepinephrine}

To determine whether endogenous NE release exerts a similar modulatory effect on excitatory and inhibitory synaptic inputs to PVN CRF neurons, we applied an optogenetic strategy to activate noradrenergic afferent inputs. An AAV9 expressing Credependent channelrhodopsin and mCherry was injected bilaterally into the nucleus of the solitary tract (NTS) of CRF-eGFP,TH-Cre mice. Following confirmation using confocal microscopy of mCherry expression in cell bodies of the NTS and in axon terminal fields in the PVN (Fig. 5A, B), we tested for an excitatory synaptic response in CRF-eGFP neurons to photostimulation of the PVN with blue light (490 nm, 2 min continuous) to activate channelrhodopsin. CRF neurons responded to photostimulation with an increase in sEPSC frequency $(355.4 \% \pm 65.8 \%, \mathrm{n}=12, \mathrm{p}<0.01)$ (Fig. $5 \mathrm{C}, \mathrm{D})$, but not amplitude or 
decay ( $\mathrm{p}=0.99,0.89$, respectively). The increase in sEPSC frequency was significantly inhibited by the $\alpha_{1}$-adrenoreceptor antagonist prazosin $(10 \mu \mathrm{M})(\mathrm{p}=0.041)$, but a significant EPSC frequency response to the photostimulation remained $(243.4 \% \pm$ $44.68 \%, \mathrm{n}=7, \mathrm{p}=0.018$ ) (Fig. 5D). Similarly, the increase in sEPSC frequency to photostimulation was significantly inhibited by blocking postsynaptic $\mathrm{G}$ protein activity in the recorded cells with GDP- $\beta-S$ application $(1 \mathrm{mM})$ via the patch pipette $(\mathrm{p}=0.03)$, but the effect of photostimulation was not completely blocked, as a significant increase in sEPSC frequency remained $(252.5 \% \pm 35.15 \%, \mathrm{n}=6, \mathrm{p}<0.01)$ (Fig. 5D). The $\alpha 1$ receptor- and G protein-independent response suggests that glutamate may be co-released from the activated noradrenergic afferents.

We also tested for the modulation of IPSCs by endogenous NE release in slices from CRF-eGFP,TH-cre mice following virally-mediated channelrhodopsin transduction in the NTS. In the presence of glutamate receptor antagonists, photostimulation failed to elicit a facilitation of sIPSCs, but caused a decrease in sIPSC frequency in all the cells tested $(48.45 \% \pm 3.95 \%$ of baseline, $n=6, p<0.01)($ Fig. $5 E, F)$.

\section{Discussion}

We found that NE stimulates $\mathrm{CRF}$ neurons by a novel dendritic signaling mechanism that activates upstream presynaptic glutamate and GABA neurons via transmission through astrocytes, as shown in our model in Fig. 6. The astrocyte participation in the retrograde signaling significantly expands the spatial domain of the signal to more distal targets than would be reached by dendritic volume transmission alone. This retrograde neuronal-glial signaling mechanism is novel because the signaling 
is not spatially restricted to the three components of the tripartite synapse, i.e., the presynaptic terminal, the postsynaptic dendrite, and the peri-synaptic astrocyte branch ${ }^{41}$. This retrograde signaling spans a potentially significant distance to the presynaptic somata/dendrites of upstream glutamate and GABA neurons to drive action potential generation. Indeed, the spatial reach of the retrograde signal could attain even greater distances if the astrocytic calcium signal were transmitted to coupled astrocytes via gap junctions. This needs to be further studied, but could explain why we saw a less robust NE facilitation of inhibitory than excitatory synaptic inputs, since the presynaptic GABA neurons are likely to be located outside the PVN (Boudaba et al., 1996; Herman et al., 2004) (but see also Jiang et al., 2018), while the presynaptic glutamate neurons may be intrinsic to the PVN and thus closer to the CRF neurons (Daftary et al., 1998; Daftary et al., 2000; Wittmann et al., 2005; Hrabovszky et al., 2005; Hrabovszky et al., 2005). Consistent with a difference in the relative distances of presynaptic glutamate and GABA neurons from the CRF neurons, the facilitation of EPSCs was seen in over $90 \%$ of recorded CRF neurons, whereas the facilitation of IPSCs occurred in 55\% of the neurons, suggesting that the presynaptic GABA neurons are more distal and fewer retain intact axonal projections to the CRF neurons in brain slices. Also, the weaker facilitation of IPSCs than EPSCs by NE ( $\mathrm{x} \square \approx 75 \%$ vs. $300 \%$, respectively, at $100 \mu \mathrm{M}$ ) may be due to the lower fidelity of the retrograde signaling to presynaptic GABA neurons because of their remote extra-nuclear location. Signaling to neurons outside the PVN is likely to require transmission through more than one astrocyte, since PVN astrocytes appear to be contained largely within the nucleus. Our findings using optogenetics also support a difference in the locations of the presynaptic glutamate and GABA neurons. 
Photostimulation of noradrenergic axons elicited an $\alpha 1$ receptor-dependent increase in glutamatergic synaptic inputs, but failed to facilitate GABAergic inputs, which is likely due to a higher threshold of activation of the retrograde signaling pathway to the presynaptic GABA neurons because of their extranuclear location and polysynaptic neuronal-glial pathway. The rightward shift in the NE concentration required to activate GABAergic inputs compared to glutamatergic inputs is consistent with a higher threshold to activate the presynaptic GABA neurons. The component of the photostimulated response that was blocked by the $\alpha 1$ antagonist ( 50\%) (Fig. 5D) suggests that the effective concentration of released $\mathrm{NE}$ was between $100 \mathrm{nM}$ and $1 \mu \mathrm{M}$, which was subthreshold for the facilitatory effect of NE on GABA release (see Fig. 1).

We found converging lines of evidence for an astrocyte intermediate in the retrograde transmission to presynaptic glutamate and GABA neurons. First, both NE and vasopressin elicited calcium responses in astrocytes. Second, the NE facilitation of synaptic inputs to the CRF neurons was lost following pretreatment of brain slices with the gliotoxin FCA. Third, the NE responses were also lost in CRF neurons from transgenic mice in which exocytosis was conditionally suppressed in astrocytes. Finally, the NE responses were blocked by antagonists of the conventional gliotransmitter, ATP. The sensitivity of the responses to the $\mathrm{P} 2 \mathrm{x}$ receptor antagonists and to TTX, and their dependence on astrocytic exocytosis, suggest that astrocytic ATP release drives action potential generation in presynaptic glutamate and GABA neurons by activating purinergic receptors, consistent with our previous findings ${ }^{37}$. Thus, the evidence for the retrograde transmission to presynaptic glutamate and GABA neurons by way of one or more intercalated astrocytes is compelling. 
A surprising discovery of this study was that the retrograde transmitter is vasopressin, which was indicated by the blockade of both the NE-induced synaptic response in CRF neurons and the calcium response in astrocytes by vasopressin receptor antagonists, but not by a CRFR1 antagonist or NO scavenger, and by a vasopressinevoked synaptic response in the CRF neurons and calcium response in astrocytes. Astrocytes express vasopressin V1a receptors (Hatton et al., 1992; Yamazaki et al., 1997) and we showed previously that vasopressin generates a calcium response in PVN astrocytes ${ }^{37}$. The source of the vasopressin could have been from neighboring PVN vasopressin neurons, but this was ruled out because ghrelin, which stimulates vasopressin release from vasopressin neuron dendrites ${ }^{37}$, had no effect on sEPSCs in the CRF neurons.

CRF neurons express vasopressin mRNA and peptide in their somata and axons basally (Whitnall et al., 1987; Lightman and Young, 1988) and increase their vasopressin expression following acute stress, chronic stress (Bartanusz et al., 1993; Baitanusz et al., 1993; Ma et al., 1997), and adrenalectomy ${ }^{55}$. Vasopressin is co-released with CRF in the median eminence and facilitates adrenocorticotrophic hormone secretion from the pituitary ${ }^{56}$. Our findings support previous studies showing that $\alpha 1$-adrenoceptor activation stimulates a vasopressin-containing subpopulation of CRF neurosecretory cells (Cummings and Seybold, 1988; Whitnall et al., 1993), and indicate that vasopressin is also released from CRF neuron dendrites.

Norepinephrine induced an $\alpha 2$ receptor-dependent suppression of sIPSCs in $45 \%$ of recorded neurons, which increased to $100 \%$ when the $\alpha 1$ receptor-mediated facilitation was blocked with TTX. Thus, the $\alpha 2$ receptor suppression of GABA release was masked 
in a subset of CRF neurons (55\%) at high NE concentration by $\alpha 1$ receptor-dependent stimulation of presynaptic GABA neurons with intact afferent axons. The two GABA responses to NE had differing concentration-dependencies, with the GABA suppression effective at lower concentration $(1 \mu \mathrm{M})$ and the facilitation emergent at higher concentrations $(>10 \mu \mathrm{M})$. The threshold concentration for the NE facilitation of excitatory inputs was lower than both, near $100 \mathrm{nM}$. The results of optogenetic stimulation are consistent with the lower threshold of NE activation of local excitatory circuits compared to inhibitory circuits, since photostimulation of the noradrenergic axons elicited a facilitation of excitatory, but not inhibitory, synaptic inputs to the CRF neurons. The combined $\alpha 1$ facilitation of excitatory inputs and $\alpha 2$ suppression of inhibitory inputs by endogenous NE would lead to a robust activation of the CRF neurons and the HPA axis. The higher threshold for the facilitation of GABA inputs may result in the recruitment of inhibitory circuits with more robust activation of the ascending noradrenergic afferents, possibly to prevent excessive activation of the HPA axis.

Our findings reconcile discrepancies between previous neuroanatomical evidence of noradrenergic synapses directly on and $\alpha 1$ adrenoreceptor expression in CRF neurons (Liposits et al., 1986; Cummings and Seybold, 1988; Flak et al., 2009; Cunningham and Sawchenko, 1988; Sawchenko and Swanson, 1982; Day et al., 1999; Cunningham et al., 1990; Füzesi et al., 2007) and electrophysiological data showing an indirect NE regulation of PVN parvocellular neurons via activation of local glutamate and GABA circuits (Daftary et al., 2000; Han et al., 2002). What functional utility is served by a complex indirect regulation of CRF neurons via retrograde activation of local synaptic circuits? The local circuits may represent a common network by which both ascending 
physiological inputs and descending psychological inputs regulate the HPA axis. While the ascending physiological inputs activate the circuits via retrograde signaling, the descending limbic inputs could activate the same circuits directly. The complex heterotypic nature of the local neuronal-glial organization provides multiple levels of modulation to regulate the circuit.

Retrograde dendritic signaling by transmission via astrocytes and astrocytic networks represents a powerful mechanism for the control by postsynaptic neurons of presynaptic neuronal ensembles, and significantly extends the domain of influence of the postsynaptic neuron over upstream afferent circuits. Whether non-neuroendocrine neurons are also capable of dendritic volume transmission dependent on astrocyte activation is not known. Neuronal-glial signaling has been described in hippocampal neurons via excitatory endocannabinoid actions on astrocytes (Navarrete and Araque, 2008; Navarrete and Araque, 2010) and in dorsal root ganglion neurons via ATP activation of satellite cells "sandwiched" between DRG somata ${ }^{61}$, but whether these forms of trans-cellular signaling can recruit distant presynaptic neurons remains to be determined.

\section{References}

1. Volterra, A. \& Meldolesi, J. Astrocytes, from brain glue to communication elements: The revolution continues. Nature Reviews Neuroscience 6, 626-640 (2005).

2. Araque, A., Parpura, V., Sanzgiri, R. P. \& Haydon, P. G. Tripartite synapses: Glia, the unacknowledged partner. Trends in Neurosciences 22, 208-215 (1999).

3. Halassa, M. M., Fellin, T. \& Haydon, P. G. The tripartite synapse: roles for gliotransmission in health and disease. Trends Mol. Med. 13, 54-63 (2007).

4. Cornell-Bell, A. H., Finkbeiner, S. M., Cooper, M. S. \& Smith, S. J. Glutamate induces calcium waves in cultured astrocytes: Long-range glial signaling. Science (80-. ). 247, 470-473 (1990). 
5. Charles, A. C., Merrill, J. E., Dirksen, E. R. \& Sandersont, M. J. Intercellular signaling in glial cells: Calcium waves and oscillations in response to mechanical stimulation and glutamate. Neuron 6, 983-992 (1991).

6. Porter, J. T. \& McCarthy, K. D. Hippocampal astrocytes in situ respond to glutamate released from synaptic terminals. J. Neurosci. 16, 5073-5081 (1996).

7. Haustein, M. D. et al. Conditions and constraints for astrocyte calcium signaling in the hippocampal mossy fiber pathway. Neuron 82, 413-429 (2014).

8. Shigetomi, E. et al. Imaging calcium microdomains within entire astrocyte territories and endfeet with GCaMPs expressed using adeno-associated viruses. $J$. Gen. Physiol. 141, 633-647 (2013).

9. Finkbeiner, S. Calcium waves in astrocytes-filling in the gaps. Neuron 8, 11011108 (1992).

10. Di, S., Popescu, I. R. \& Tasker, J. G. Glial control of endocannabinoid heterosynaptic modulation in hypothalamic magnocellular neuroendocrine cells. $J$. Neurosci. 33, (2013).

11. Wu, N. \& Tasker, J. G. Nongenomic Glucocorticoid Suppression of a Postsynaptic Potassium Current via Emergent Autocrine Endocannabinoid Signaling in Hypothalamic Neuroendocrine Cells following Chronic Dehydration. eneuro 4, ENEURO.0216-17.2017 (2017).

12. Son, S. J. et al. Dendritic Peptide Release Mediates Interpopulation Crosstalk between Neurosecretory and Preautonomic Networks. Neuron (2013). doi:10.1016/j.neuron.2013.04.025

13. Ludwig, M. et al. Intracellular calcium stores regulate activity-dependent neuropeptide release from dendrites. Nature 418, 85-89 (2002).

14. Kombian, S. B., Mouginot, D. \& Pittman, Q. J. Dendritically released peptides act as retrograde modulators of afferent excitation in the supraoptic nucleus in vitro. Neuron 19, 903-912 (1997).

15. Oliet, S. H. R., Baimoukhametova, D. V., Piet, R. \& Bains, J. S. Retrograde Regulation of GABA Transmission by the Tonic Release of Oxytocin and Endocannabinoids Governs Postsynaptic Firing. J. Neurosci. 27, 1325-1333 (2007).

16. de Kock, C. P. J. et al. Somatodendritic secretion in oxytocin neurons is upregulated during the female reproductive cycle. J. Neurosci. 23, 2726-34 (2003).

17. Itoi, K. et al. Microinjection of norepinephrine into the paraventricular nucleus of the hypothalamus stimulates corticotropin-releasing factor gene expression in conscious rats. Endocrinology 135, 2177-2182 (1994).

18. Plotsky, P. M. Facilitation of immunoreactive corticotropin-releasing factor 
secretion into the hypophysial-portal circulation after activation of catecholaminergic pathways or central norepinephrine injection. Endocrinology 121, 924-930 (1987).

19. Cole, R. L. \& Sawchenko, P. E. Neurotransmitter regulation of cellular activation and neuropeptide gene expression in the paraventricular nucleus of the hypothalamus. J. Neurosci. 22, 959-969 (2002).

20. Itoi, K., Helmreich, D. L., Lopez-Figueroa, M. O. \& Watson, S. J. Differential regulation of corticotropin-releasing hormone and vasopressin gene transcription in the hypothalamus by norepinephrine. J. Neurosci. 19, 5464-5472 (1999).

21. Helmreich, D. L., Itoi, K., Lopez-Figueroa, M. O., Akil, H. \& Watson, S. J. Norepinephrine-induced $\mathrm{CRH}$ and AVP gene transcription within the hypothalamus: Differential regulation by corticosterone. Mol. Brain Res. 88, 6273 (2001).

22. Sawchenko, P. E. \& Swanson, L. W. The organization of noradrenergic pathways from the brainstem to the paraventricular and supraoptic nuclei in the rat. 275325 (1982). doi:10.1016/0165-0173(82)90010-8

23. Cunningham, E. T. \& Sawchenko, P. E. Anatomical specificity of noradrenergic inputs to the paraventricular and supraoptic nuclei of the rat hypothalamus. $J$. Comp. Neurol. 274, 60-76 (1988).

24. Flak, J. N. et al. Role of paraventricular nucleus-projecting norepinephrine/epinephrine neurons in acute and chronic stress. Eur. J. Neurosci. 39, 1903-1911 (2014).

25. Woulfe, J. M., Flumerfelt, B. A. \& Hrycyshyn, A. W. Efferent connections of the A1 noradrenergic cell group: A DBH immunohistochemical and PHA-L anterograde tracing study. Exp. Neurol. 109, 308-322 (1990).

26. Flak, J. N., Ostrander, M. M., Tasker, J. G. \& Herman, J. P. Chronic stress-induced neurotransmitter plasticity in the PVN. J Comp Neurol 517, 156-165 (2009).

27. Herman, J. P., Mueller, N. K. \& Figueiredo, H. Role of GABA and glutamate circuitry in hypothalamo-pituitary- adrenocortical stress integration. in Annals of the New York Academy of Sciences 1018, 35-45 (2004).

28. Ziegler, D. R., Edwards, M. R., Ulrich-Lai, Y. M., Herman, J. P. \& Cullinan, W. E. Brainstem origins of glutamatergic innervation of the rat hypothalamic paraventricular nucleus. J. Comp. Neurol. 520, 2369-2394 (2012).

29. Cummings, S. \& Seybold, V. Relationship of alpha-1- and alpha-2-adrenergicbinding sites to regions of the paraventricular nucleus of the hypothalamus containing corticotropin-releasing factor and vasopressin neurons. Neuroendocrinology 47, 523-532 (1988).

30. Day, H. E., Campeau, S., Watson, S. J. \& Akil, H. Distribution of alpha 1a-, alpha 
1b- and alpha 1d-adrenergic receptor mRNA in the rat brain and spinal cord. $J$. Chem. Neuroanat. 13, 115-139 (1997).

31. Daftary, S. S., Boudaba, C. \& Tasker, J. G. Noradrenergic regulation of parvocellular neurons in the rat hypothalamic paraventricular nucleus. Neuroscience 96, 743-751 (2000).

32. Han, S. K. et al. Noradrenaline excites and inhibits GABAergic transmission in parvocellular neurons of rat hypothalamic paraventricular nucleus. J Neurophysiol 87, 2287-2296 (2002).

33. Liposits, Z., Phelix, C. \& Paull, W. K. Adrenergic innervation of corticotropin releasing factor (CRF) - synthesizing neurons in the hypothalamic paraventricular nucleus of the rat - A combined light and electron microscopic immunocytochemical study. Histochemistry 84, 201-205 (1986).

34. Day, H. E., Campeau, S., Watson, S. J. \& Akil, H. Expression of alpha(1b) adrenoceptor mRNA in corticotropin-releasing hormone-containing cells of the rat hypothalamus and its regulation by corticosterone. J. Neurosci. (1999). doi:02706474/99/1910098-09\$05.00/0

35. Whitnall, M. H., Kiss, A. \& Aguilera, G. Contrasting effects of central alpha-1adrenoreceptor activation on stress-responsive and stress-nonresponsive subpopulations of corticotropin-releasing hormone neurosecretory cells in the rat. Neuroendocrinology 58, 42-48 (1993).

36. de Goeij, D. C. E. et al. Repeated stress-induced activation of corticotropinreleasing factor neurons enhances vasopressin stores and colocalization with corticotropin-releasing factor in the median eminence of rats. Neuroendocrinology 53, 150-159 (1991).

37. Haam, J., Halmos, K. C., Di, S. \& Tasker, J. G. Nutritional State-Dependent Ghrelin Activation of Vasopressin Neurons via Retrograde Trans-Neuronal-Glial Stimulation of Excitatory GABA Circuits. J. Neurosci. (2014). doi:10.1523/JNEUROSCI.3178-13.2014

38. Paulsen, R. E., Contestabile, A., Villani, L. \& Fonnum, F. An Invivo Model for Studying Function Of Brain-Tissue Temporarily Devoid Of Glial-Cell Metabolism - the Use Of Fluorocitrate. J. Neurochem. 48, 1377-1385 (1987).

39. Swanson, R. A. \& Graham, S. H. Fluorocitrate and fluoroacetate effects on astrocyte metabolism in vitro. Brain Res. 664, 94-100 (1994).

40. Mulligan, S. J. \& MacVicar, B. A. Calcium transients in astrocyte endfeet cause cerebrovascular constrictions. Nature 431, 195-199 (2004).

41. Perea, G. \& Araque, A. Communication between astrocytes and neurons: A complex language. J. Physiol. Paris 96, 199-207 (2002).

42. Boudaba, C., Szabó, K., Tasker, J. G., Szabo, K. \& Tasker, J. G. Physiological 
mapping of local inhibitory inputs to the hypothalamic paraventricular nucleus. $J$. Neurosci. 16, 7151-60 (1996).

43. HERMAN, J. P., MUELLER, N. K. \& FIGUEIREDO, H. Role of GABA and Glutamate Circuitry in Hypothalamo-Pituitary-Adrenocortical Stress Integration. Ann. New York Acad. Sci. 1018, 35-45 (2004).

44. Jiang, Z., Rajamanickam, S. \& Justice, N. J. Local Corticotropin-Releasing-Factor Signaling in the Hypothalamic Paraventricular Nucleus. J. Neurosci. 38, 1492-17 (2018).

45. Daftary, S. S., Boudaba, C., Szabó, K. \& Tasker, J. G. Noradrenergic excitation of magnocellular neurons in the rat hypothalamic paraventricular nucleus via intranuclear glutamatergic circuits. J. Neurosci. 18, 10619-10628 (1998).

46. Wittmann, G., Lechan, R. M., Liposits, Z. \& Fekete, C. Glutamatergic innervation of corticotropin-releasing hormone- and thyrotropin-releasing hormonesynthesizing neurons in the hypothalamic paraventricular nucleus of the rat. Brain Res. 1039, 53-62 (2005).

47. Hrabovszky, E., Wittmann, G., Turi, G. F., Liposits, Z. \& Fekete, C. Hypophysiotropic thyrotropin-releasing hormone and corticotropin-releasing hormone neurons of the rat contain vesicular glutamate transporter-2. Endocrinology 146, 341-347 (2005).

48. Hatton, G. I., Bicknell, R. J., Hoyland, J., Bunting, R. \& Mason, W. T. Arginine vasopressin mobilises intracellular calcium via V1-receptor activation in astrocytes (pituicytes) cultured from adult rat neural lobes. Brain Res. 588, 75-83 (1992).

49. Yamazaki, R. S., Chen, Q., Schreiber, S. S. \& Brinton, R. D. Localization of V1a vasopressin receptor mRNA expression in cultured neurons, astroglia, and oligodendroglia of rat cerebral cortex. Brain Res Mol Brain Res 45, 138-140 (1997).

50. Whitnall, M. H., Smyth, D. \& Gainer, H. Vasopressin coexists in half of the corticotropin-releasing factor axons present in the external zone of the median eminence in normal rats. Neuroendocrinology 45, 420-424 (1987).

51. Lightman, S. L. \& Young, W. S. Corticotrophin $\square$ releasing factor, vasopressin and pro $\square$ opiomelanocortin mRNA responses to stress and opiates in the rat. J. Physiol. 403, 511-523 (1988).

52. Bartanusz, V. et al. Stress-induced increase in vasopressin and corticotropinreleasing factor expression in hypophysiotrophic paraventricular neurons. Endocrinology 132, 895-902 (1993).

53. Baitanusz, V., Aubry, J. M., Jezova, D., Baffi, J. \& Kiss, J. Z. Up-regulation of vasopressin mRNA in paraventricular hypophysiotrophic neurons after acute immobilization stress. Neuroendocrinology 58, 625-629 (1993). 
54. Ma, X. M., Levy, A. \& Lightman, S. L. Rapid changes in heteronuclear RNA for corticotrophin-releasing hormone and arginine vasopressin in response to acute stress. J. Endocrinol. 152, 81-89 (1997).

55. Kovács, K. J., Földes, a \& Sawchenko, P. E. Glucocorticoid negative feedback selectively targets vasopressin transcription in parvocellular neurosecretory neurons. J. Neurosci. 20, 3843-3852 (2000).

56. Whitnall, M. H., Mezey, E. \& Gainer, H. Co-localization of corticotropin-releasing factor and vasopressin in median eminence neurosecretory vesicles. Nature $\mathbf{3 1 7}$, 248-250 (1985).

57. Cunningham, E. T., Bohn, M. C. \& Sawchenko, P. E. Organization of adrenergic inputs to the paraventricular and supraoptic nuclei of the hypothalamus in the rat. $J$. Comp. Neurol. 292, 651-667 (1990).

58. Füzesi, T., Wittmann, G., Liposits, Z., Lechan, R. M. \& Fekete, C. Contribution of noradrenergic and adrenergic cell groups of the brainstem and agouti-related protein-synthesizing neurons of the arcuate nucleus to neuropeptide-Y innervation of corticotropin-releasing hormone neurons in hypothalamic paraventricular nucle. Endocrinology 148, 5442-5450 (2007).

59. Navarrete, M. \& Araque, A. Endocannabinoids Mediate Neuron-Astrocyte Communication. Neuron 57, 883-893 (2008).

60. Navarrete, M. \& Araque, A. Endocannabinoids potentiate synaptic transmission through stimulation of astrocytes. Neuron 68, 113-126 (2010).

61. Rozanski, G. M., Li, Q. \& Stanley, E. F. Transglial transmission at the dorsal root ganglion sandwich synapse: Glial cell to postsynaptic neuron communication. Eur. J. Neurosci. 37, 1221-1228 (2013). 


\section{Figure Legends}

Figure 1. Norepinephrine regulation of CRF neurons via local synaptic circuits. A. Loose-seal patch clamp recording of the spiking response of a CRF neuron to bath application of $\mathrm{NE}(100 \mu \mathrm{M})$ and the increased response following blockade of $\mathrm{GABA}_{\mathrm{A}}$ receptors with picrotoxin (PTX) and decreased response following blockade of glutamate receptors with DNQX/APV. B. Time series of changes in spike frequency prior to $(-5-0$ $\min )$, during $(0-5 \mathrm{~min})$, and after NE application $(100 \mu \mathrm{M})$ in control solution, PTX, and DNQX/APV. C. Mean spike frequency responses to NE without (Control) and with the $\mathrm{GABA}_{\mathrm{A}}(\mathrm{PTX})$ and glutamate receptor antagonists (DNQX/APV). D. Whole-cell recording of the NE $(100 \mu \mathrm{M})$ effect on sEPSCs in a CRF neuron recorded in bicuculline to block inhibitory synaptic currents. E. Time plot of the NE $(100 \mu \mathrm{M})$ effect on the frequency of sEPSCs. F. The NE effect was concentration-dependent, with a threshold concentration $\sim 0.1 \mu \mathrm{M}$. G. The NE-induced increase in sEPSC frequency was blocked by TTX, suggesting spike-dependence. H. Whole-cell recording of the NE (100 $\mu \mathrm{M})$ effect on sIPSCs in a CRF neuron recorded in DNQX/APV to block excitatory synaptic currents. Norepinephrine caused an increase in sIPSCs in some cells (1) and a decrease in sIPSCs in others (2). I. Time plots of the normalized changes in mean sIPSC frequency in response to $\mathrm{NE}$ in different cohorts of $\mathrm{CRH}$ neurons. J. Norepinephrine either increased or decreased the frequency of sIPSCs relative to baseline, suggesting presynaptic sites of modulation. The NE-induced increase, but not the decrease, in sIPSC frequency was blocked by TTX, suggesting the facilitation, but not the suppression, of sIPSCs by NE was spike-dependent. K. The two sIPSC responses to NE had differing concentration 
dependencies, with the NE-induced suppression of sIPSCs dominant at lower concentrations and the NE-induced facilitation emerging in some, but not all recorded cells at higher concentrations of NE.

Figure 2. Adrenoreceptor dependence of norepinephrine effects on excitatory and inhibitory synaptic inputs to CRF neurons. A. The NE-induced facilitation of sEPSCs was blocked by the $\alpha 1$ receptor antagonist prazosin. B. The $\alpha 1$ receptor agonist phenylephrine, like norepinephrine, increased sEPSC frequency. C. Summary of $\alpha 1$ receptor agonist and antagonist effects on sEPSC frequency. D. The $\alpha 1$ receptor antagonist prazosin blocked the norepinephrine-induced increase in sIPSC frequency, but not the decrease in SIPSC frequency. E. Summary of $\alpha 1$ receptor antagonist effect on the facilitation and suppression of sIPSCs. F. The $\alpha 2$ receptor antagonist yohimbine blocked the norepinephrine-induced decrease in sIPSC frequency isolated in TTX. G. Summary of $\alpha 2$ receptor antagonist effect on NE-induced suppression of sIPSCs.

Fig. 3. Norepinephrine regulation of synaptic inputs to CRF neurons requires dendritic release of vasopressin. A. The NE-induced increase in sEPSC frequency is blocked by intracellular application of a G-protein blocker, GDP- $\beta$ s, in the CRF neurons. B. Average sEPSC frequency changes in response to NE in control CRF neurons (NE) and in CRF neurons in which G-protein activity has been blocked with GDP- $\beta$ s. C. Time plots of the NE-induced increase in sIPSC frequency, which is blocked by blocking postsynaptic G protein activity, and decrease in sIPSC frequency, which is resistant to postsynaptic Gprotein blockade. D. Average sIPSC frequency facilitation $(\mathrm{NE}(+))$ and suppression 
(NE(-)) to NE without and with GDP- $\beta$ s in the patch pipettes. The facilitation of sIPSCs by NE was blocked, but the suppression of sIPSCs was maintained during postsynaptic G protein inhibition. E. The vasopressin V1a receptor antagonist SR 49059 blocked the NEinduced increase in sEPSC frequency and puff application of vasopressin (VP) elicited a similar increase in sEPSC frequency.

Fig. 4. Dependence of the NE effects on astrocytes. A. The NE-induced increase in sEPSC frequency is inhibited by preincubation of slices in the gliotoxin FCA. B. Mean sEPSC frequency changes in NE $(100 \mu \mathrm{M})$ relative to baseline in control slices and slices incubated in FCA. C. The NE-induced increase in sIPSC frequency is sensitive to the gliotoxin FCA, but not the NE-induced decrease in sIPSC frequency. D. Mean NEinduced increase $(\mathrm{NE}(+))$ and decrease $(\mathrm{NE}(-))$ in sIPSC frequency relative to baseline following FCA treatment. The NE-induced increase in sIPSC frequency $(\mathrm{NE}(+))$, but not the decrease in sIPSC frequency (NE(-)), was blocked by FCA preincubation. E. The NEinduced increase in sEPSC frequency was blocked by the P2 purinergic receptor antagonist PPADS. F. The NE-induced increase in sIPSC frequency was blocked by the $\mathrm{P} 2 \mathrm{x}$ purinergic receptor antagonist, TNP-ATP, but the NE-induced decrease in sIPSC frequency was not. G. Fluorescence image showing the glial $\mathrm{Ca}^{2+}$ response to $\mathrm{NE}$ in the PVN with a glia-specific Rhod-2 $\mathrm{AM} \mathrm{Ca}{ }^{2+}$ indicator. H. Fluorescence image of the glial $\mathrm{Ca}^{2+}$ response to vasopressin. I. Quantification of glial $\mathrm{Ca}^{2+}$ responses to NE, which is blocked by the vasopressin receptor blocker Manning Compound (NE/MC), and to vasopressin (VP). J. The NE effect on sEPSCs is maintained in Tet-off dn-SNARE mice maintained on a doxycycline (Dox) diet, partially blocked following 3 weeks of removal 
of Dox diet, and almost completely lost following 5 weeks off the Dox diet. ${ }^{*}, \mathrm{p}<0.05$; **, $\mathrm{p}<0.01 ; \#, \mathrm{p}<0.05$ and \#\#, $\mathrm{p}<0.01$ vs. indicated groups.

Fig. 5. Endogenous norepinephrine modulation of excitatory and inhibitory synaptic inputs to the CRF neurons. A. ChR2-mCherry expression in $\mathrm{TH}$-expressing neurons in the NTS. B. CRF-eGFP expression in neurons and ChR2-mCherry expression in THcontaining axons in the PVN. C. Recording of sEPSCs in a CRF-eGFP neuron in the PVN before (Baseline) and after photostimulation of ChR2 in the presence of GABA receptor antagonist. D. The sEPSC frequency response to photostimulation before and after blocking $\alpha 1$ receptors with prazosin and postsynaptic $G$ protein activity with intracellular GDP- $\beta$ s. E. Recording of sIPSCs in a CRF-eGFP neuron before (Baseline) and after photostimulation of $\mathrm{ChR} 2$ in the presence of glutamate receptor antagonists. $\mathrm{F}$. Time plot of sIPSC frequency response to photostimulation relative to baseline frequency.

Figure 6. Model of the noradrenergic regulation of CRF neurons. Norepinephrine activates postsynaptic $\alpha 1$ adrenoreceptors on CRF neurons and presynaptic $\alpha 2$ receptors on GABA terminals. $\alpha 1$ receptor activation triggers the dendritic release of vasopressin, which stimulates the astrocytic release of ATP. ATP acts on upstream glutamate and GABA neurons to stimulate spiking, which activates recurrent excitatory and inhibitory inputs to the CRF neurons. Presynaptic $\alpha 2$ receptor activation suppresses the release of GABA. The combined activation of presynaptic glutamate neurons and suppression of GABA release causes excitation of the CRF neurons, which is constrained at higher concentrations of NE by activation of presynaptic GABA neurons. 
Figure 1

A

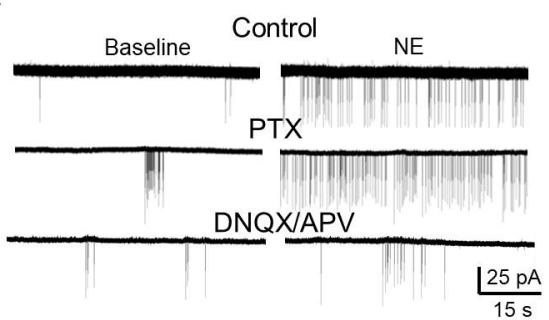

D<smiles>[3H]</smiles>

Baseline

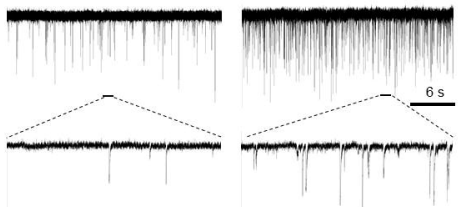

$20 \mathrm{pA}$
B

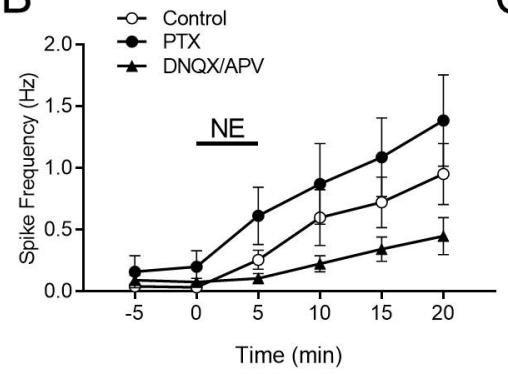

$\mathrm{F}$

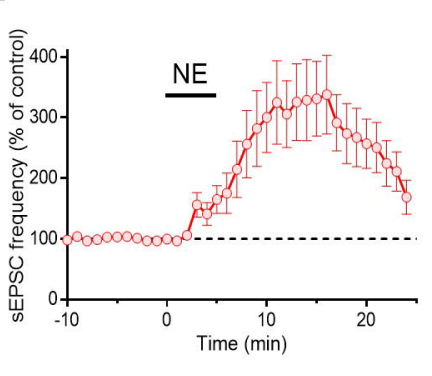

C

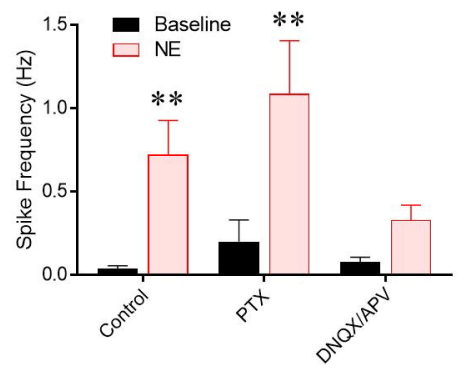

G

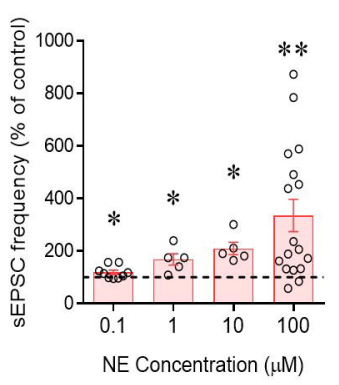

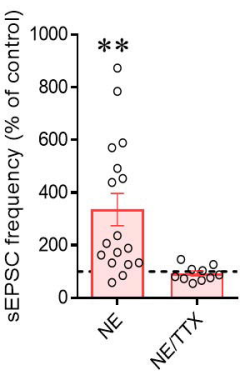

K
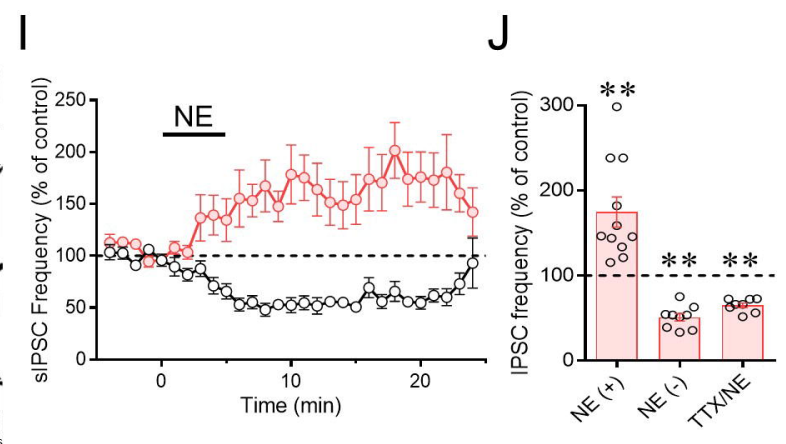

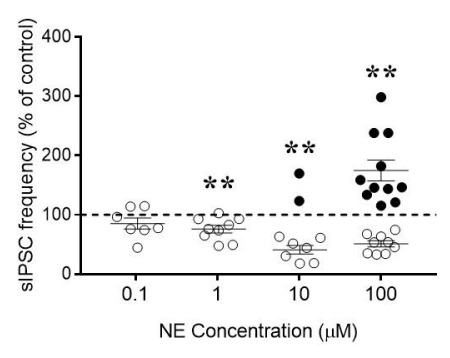

K 
Figure 2
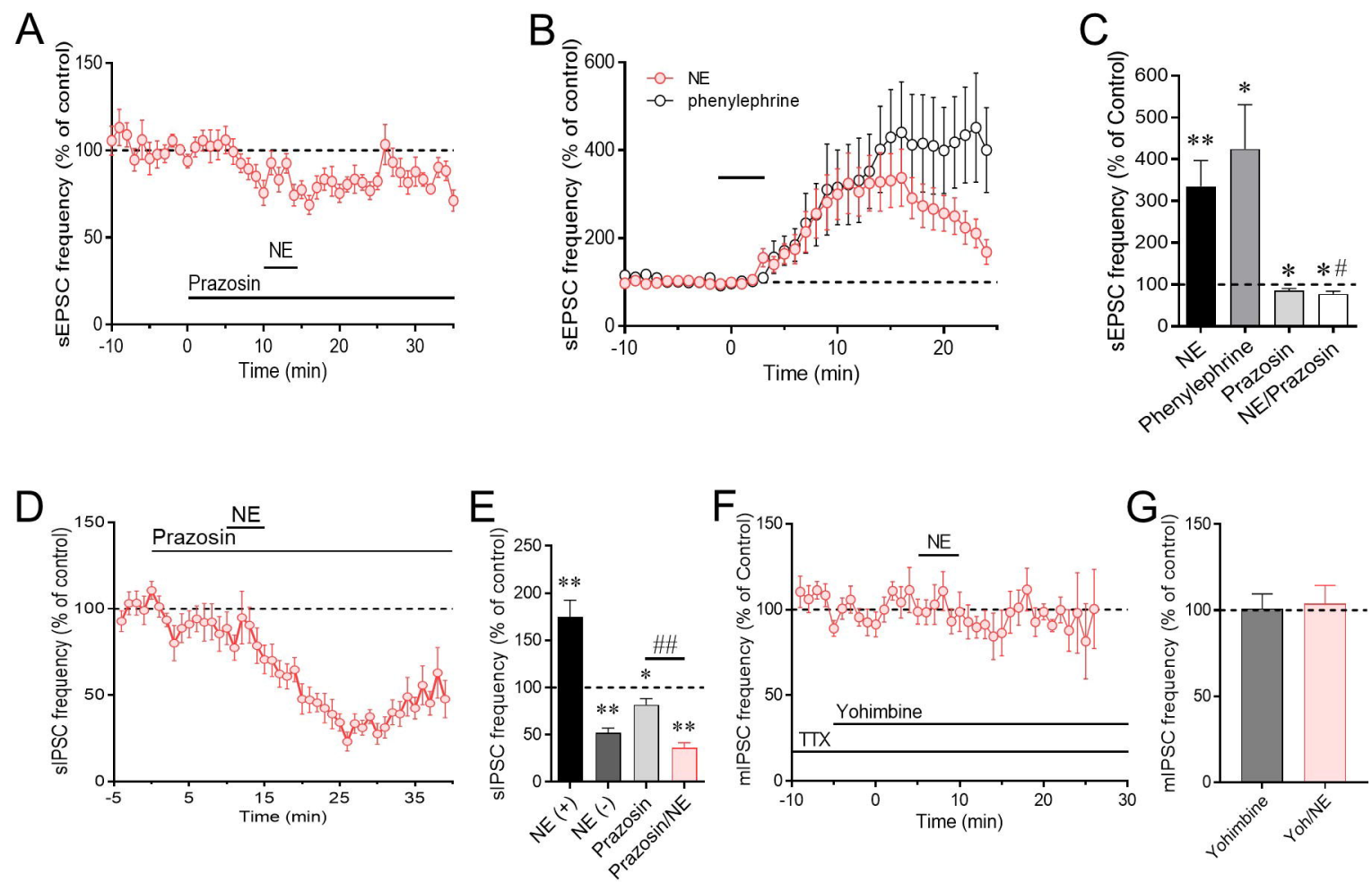
Figure 3
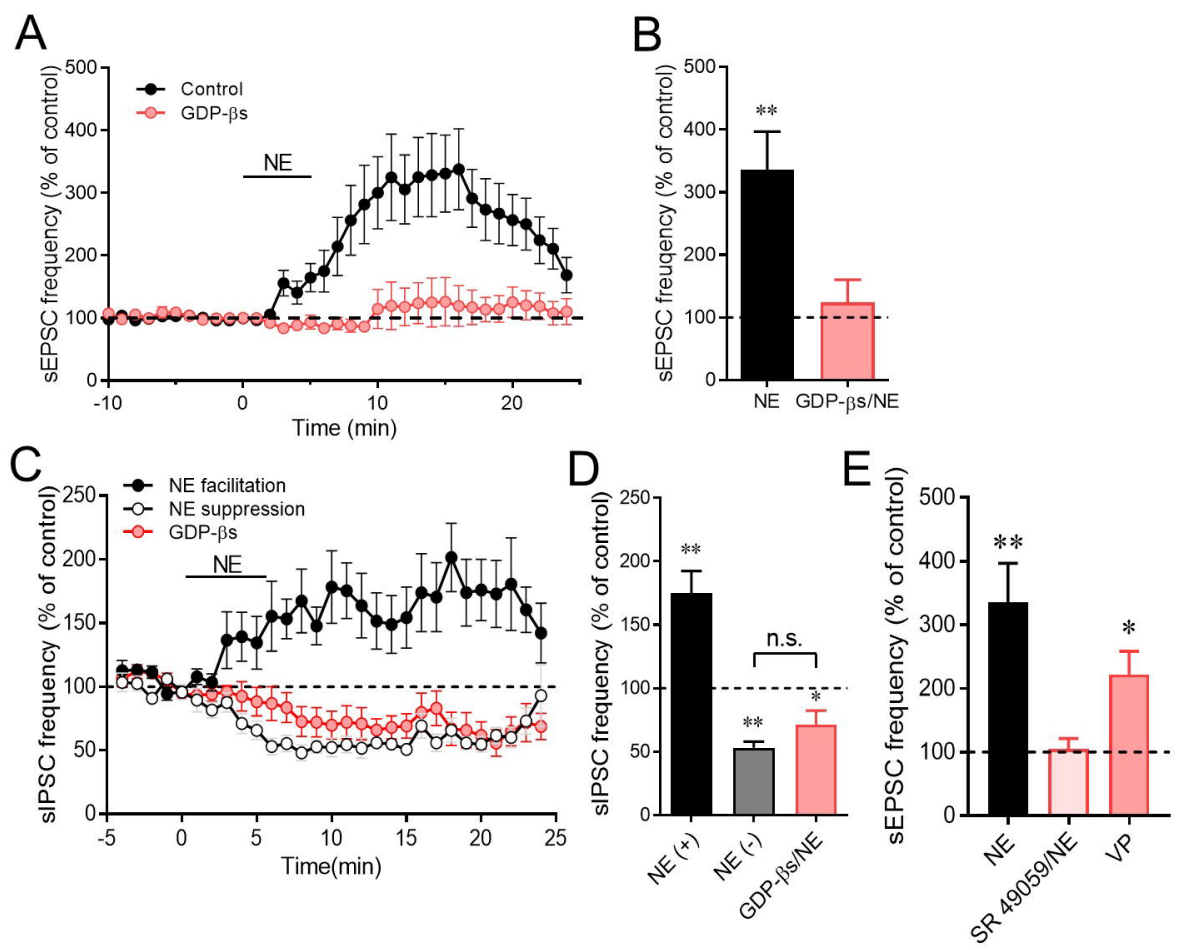
Figure 4
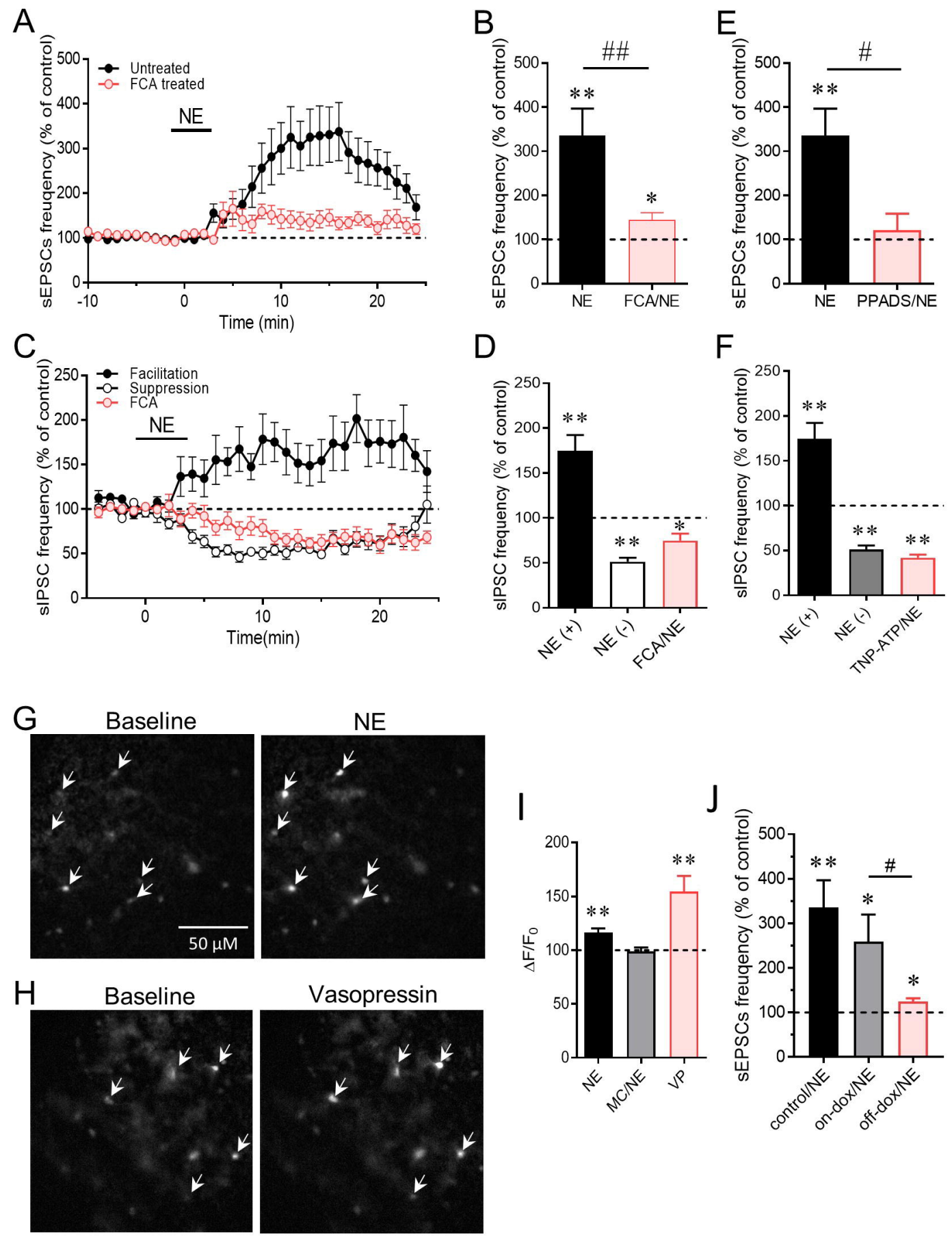
Figure 5

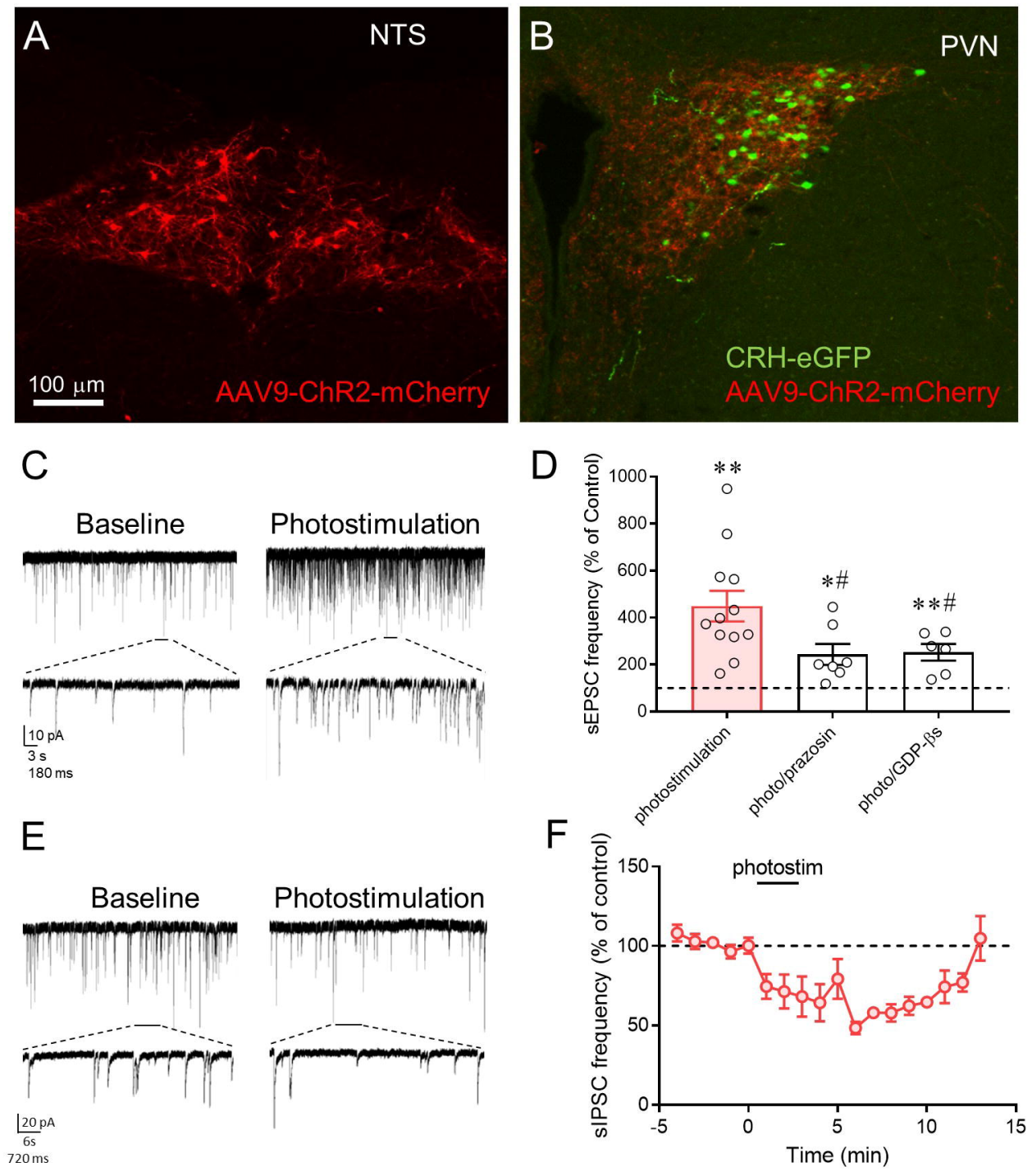


Figure 6

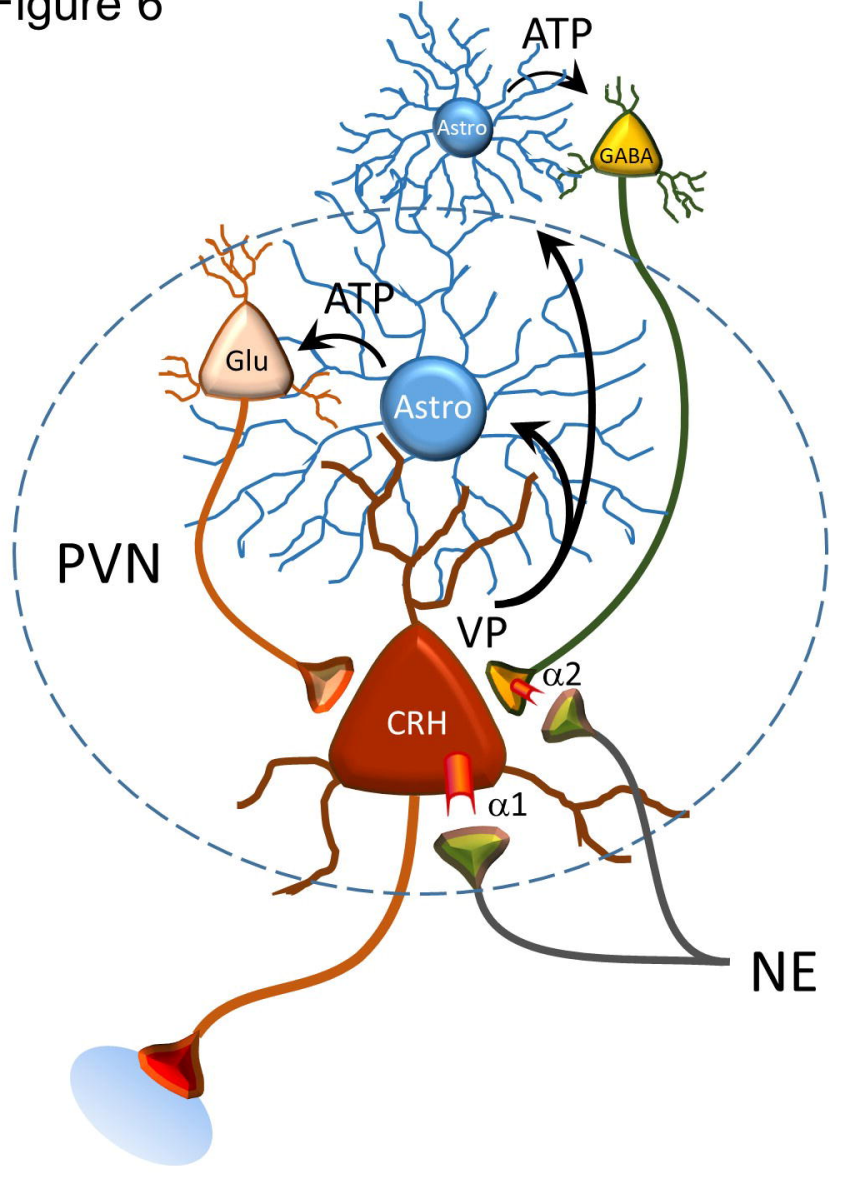

